\title{
ПРАВОВЫЕ ОСНОВЫ ПОВЫШЕНИЯ ИНКЛЮЗИВНОСТИ ГОСУДАРСТВЕННОЙ ГРАЖДАНСКОЙ СЛУЖБЫ: ПЕРСПЕКТИВЫ РАЗВИТИЯ В РОССИИ И ОПЫТ США
}

\author{
(C) 2020 Гирфанова Арина Радиковна
}

студентка 4 курса бакалавриата

Институт государственной службы и управления Российской академии народного хозяйства и государственной службы при Президенте Российской Федерации, Россия, Москва

E-mail: arina.girfanova@yandex.ru

\section{(c) 2020 Семин Алексей Николаевич}

студент 4 курса бакалавриата

Институт государственной службы и управления Российской академии народного хозяйства и государственной службы при Президенте Российской Федерации, Россия, Москва

E-mail: AlexSemin1403@yandex.ru

В России гарантируется социальное обеспечение инвалидов, в том числе оказывается помощь в трудоустройстве. Вместе с тем из более чем 3,4 миллиона инвалидов не трудоустроено 73\%. Государство не занимается вопросом инклюзивности государственной службы. Для изучения инструментов повышения доступности государственной службы необходимо рассмотреть релевантный опыт США, который доказывает успешность применения комплексных методов привлечения инвалидов на государственную службу за счет создания доступной рабочей среды, внедрения специализированных образовательных программ и упрощения конкурсных процедур. На основании изученного опыта авторами предложен ряд практических рекомендаций.

Ключевые слова: государственная гражданская служба, лица с ограниченными возможностями здоровья, конкурсные процедуры, квотирование, инклюзивность, правовое регулирование государственной службы.

На сегодняшний день одним из ключевых трендов является широкомасштабное повышение инклюзивности. При этом в зарубежных странах на повестку дня выносится главная тенденция - работа над инклюзивностью государственной службы.

В Российской Федерации складывается двоякая ситуация. С одной стороны, согласно Конституции, в Российской Федерации гарантируется социальное обеспечение инвалидов, Федеральный закон N 181-Ф3 «О социальной защите инвалидов в Российской Федерации» регламентирует понятие социальной защиты инвалидов, целью которой является создание равных с другими гражданами возможностей участия в жизни общества. Что более важно, статьей 21 данного закона устанавливается необходимость введения квот для приема на работу инвалидов. Квоты должны устанавливаться законом субъекта Российской Федерации для работодателей, численность работников которых превышает 100 человек. С другой стороны, эти требования не распространяются ни на государственную гражданскую службу, ни на муниципальную службу. Законодательство не предусматривает возможность упрощения или модификации конкурсных процедур. Более того, Федеральным законом от 27.07.2004 N 79-ФЗ (ред. от 16.12.2019) «О государственной гражданской службе Российской Федерации» и Приказом Минздравсоцразвития РФ от 14.12.2009 N 984н [1] устанавливается перечень заболеваний, препятствующих поступлению и прохождению государственной службы. Признавая необходимость подобных ограничений, необходимо отметить низкую гибкость существующих конкурсных процедур, что препятствует повышению инклюзивности государственной службы. Не менее важно и то, что попытки субъектов распространить практику квотирования и на государственную службу субъекта РФ были пресечены Определением Верховного Суда РФ [2], согласно которому упрощение конкурсных процедур для инвалидов противоречит принципу единства правовых и организационных основ федеральной гражданской службы и гражданской службы субъектов Российской Федерации.

Необходимо понимать, что повышение 
инклюзивности государственной службы представляет не косметическую меру, а имеет ряд четких мотивов:

- лица с ограниченными возможностями испытывают объективные сложности при трудоустройстве, это отражают статистические показатели: уровень безработицы среди инвалидов трудоспособного возраста равен 73,52\% [3], в сравнении с общим уровнем безработицы в $4,7 \%$;

- государство упускает из поля зрения собственную роль работодателя: для организаций устанавливаются требования по квотированию рабочих мест для инвалидов, при этом нет объективных причин, по которым аналогичные требования не могут распространяться на должности государственной гражданской службы или муниципальной службы;

- привлечение инвалидов на гражданскую службу повышает репрезентативность: на сегодняшний день в сфере государственного управления занято 7,1\% всего населения в возрасте 15-72 года, тогда как из числа лиц с ограниченными возможностями той же возрастной категории - 3,8\% [4]. Диспропорция свидетельствует о том, что доступ к государственной службе на практике не является действительно равным;

Повышение инклюзивности государственной службы - процесс, требующий реализации комплекса мероприятий. Таким образом, видится необходимым принятие мер по реформе законодательства в данной области с целью упрощения доступа инвалидов к государственной гражданской службе. Рассмотрим релевантные зарубежные примеры повышения инклюзивности государственной службы.

Обратимся к опыту США, где первые базисные положения о повышении инклюзивности государственной гражданской службы были заложены Законом о реабилитации 1973 года (англ. Rehabilitation Act of 1973) [5]. Согласно разделу 501 данного закона, федеральные государственные органы не только не имеют права устанавливать дискриминационные требования, препятствующие найму инвалидов, но и обязаны разрабатывать планы «позитивных действий» (англ. affirmative actions - политика позитивной дискриминации или мер выравнивания, направленных на предоставление преимуществ определенным группам населения с целью сглаживания различий). Более подробно эти положения были раскрыты в Законе об американцах- инвалидах 1990 года (англ. Americans with Disabilities Act of 1990) [6], установившем обязанность всех работодателей, численность работников которых составляет не менее 15 человек, не только не дискриминировать инвалидов при трудоустройстве, но и производить любые «разумные изменения» рабочего места для повышения его доступности для лиц с ограниченными возможностями здоровья. Кроме того, вышеозначенные акты расширили полномочия Комиссии по равным возможностям в сфере занятости (англ. Equal Employment Opportunity Commission), созданной в 1965 году с целью борьбы с дискриминацией на рабочем месте по признаку пола, расы и возраста. Директивой 715 [11] Комиссии устанавливается обязанность федеральных органов по разработке типовых стратегий найма инвалидов и программ по сохранению их рабочих мест.

Следующим крупным шагом по увеличению степени инклюзивности федеральных органов стал Указ Президента США № 13163 [8] 2000 года, в соответствии с которым в течение 5 лет в федеральные органы должно было быть привлечено 100000 новых сотрудников с ограниченными возможностями здоровья. Каждому органу было поручено подготовить план по расширению возможностей трудоустройства для инвалидов и дополнительные программы популяризации государственной службы среди них. Для обеспечения мониторинга процесса каждый федеральный орган обязан передавать статистику Управлению кадровой службы (англ. Office of Personnel Management) для последующей публикации.

Важнейшим нововведением стал так называемый Табель А (англ. Schedule A) - часть механизма, позволяющего нанимать инвалидов с нарушениями здоровья, включенными в данный перечень, без соблюдения сроков и процедур, установленных нормативными актами. В список входит ряд нарушений сенсорной системы (слепота, глухота), психические расстройства, отсутствие конечностей, паралич, эпилепсия и некоторые другие заболевания. Примечательно, что список включает в себя исключительно тяжелые формы инвалидности, что безусловно свидетельствует о стремлении к облегчению процесса трудоустройства лиц, находящихся в группе наибольшего риска. Такой подход позволяет говорить о высокой степени инклюзивности всей системы найма.

По данным Совета по защите системы заслуг 
(англ. Merit Systems Protection Board), процедура найма нового государственного гражданского служащего занимает около 102 дней [10], лицо, включенное в Табель А, может быть нанято уполномоченным служащим без прохождения конкурсного отбора в максимально короткие сроки. Однако, несмотря на акцент на найме лиц с вышеперечисленными тяжелыми формами инвалидности, их доля в общем количестве государственных гражданских служащих федерального уровня не превышает $1 \%$, при этом около $50 \%$ из них работают на низкооплачиваемых должностях, не требующих значительной квалификации и менее 6\% выполняют высокооплачиваемую работу. Необходимо отметить, что данная статистика может являться результатом объективных ограничений здоровья таких государственных служащих, однако, результаты программы признаются неудовлетворительными.

В 2010 году Президентом Обамой были возобновлены усилия по привлечению лиц с ограниченными возможностями здоровья на государственную гражданскую службу. Указом Президента США № 13548 [7] декларируется цель федерального правительства как крупнейшего работодателя выработать оптимальную модель по найму инвалидов. Наиболее важно, что Указом были установлены новые детально проработанные целевые показатели, численные цели и отдельные подцели по заболеваниям, включенным в Табель А. На Управление кадровой службы были возложены обязанности по разработке типовых стратегий найма и учебных программ для сотрудников отдела кадров.

Однако наиболее важны результаты этих целенаправленных усилий - обратимся к данным Бюро статистики Министерства труда США. На 2019 год 19,3\% людей с ограниченными возможностями здоровья было трудоустроено, при ограничении выборки по возрасту 16-64 показать растет и достигает 30,9\%. Однако наиболее показательны следующие данные: $13,3 \%$ работающих инвалидов трудоустроены в государственном секторе (федеральный уровень + уровень штатов + муниципальный уровень) [9] - этот показатель равен аналогичному для лиц без ограничения возможностей здоровья, что позволяет сделать вывод о практически равном доступе к государственной и муниципальной службе вне зависимости от ограничений здоровья. Более того, на федеральном уровне работают $2,4 \%$ от всех лиц без инвалидности, находящихся на рынке труда и 2,9\% от трудоустроенных инвалидов. Необходимо учитывать, что подавляющее большинство инвалидов не включены в состав рабочей силы (около 70,9\%), так как их трудовой статус не известен, либо они не ищут работу. В 2015 году Управлением кадровой службы был опубликован последний подробный отчет о трудоустройстве инвалидов в федеральных органах исполнительной власти, так из более 1,8 миллиона служащих 173977 - лица с ограниченными возможностями здоровья (9,46\%), дополнительно учитываются ветераны боевых действий, получившие инвалидность в ходе службы, с ними количество возрастает до 264844 человек (14,41\% от общего числа служащих) [12]. Для оценки масштабов отметим, что, например, в Министерстве национальной безопасности, являющимся 3-м крупнейшим работодателем федерального уровня, всего трудоустроено 166777 человек.

Таким образом, американский опыт по повышению инклюзивности государственной гражданской службы можно назвать успешным. Некоторые подходы и механизмы, в частности ускоренное трудоустройство и адаптация рабочих мест, могут быть заимствованы с учетом разницы в законодательстве и структуре рынка труда.

Для повышения инклюзивности государственной гражданской службы необходимо применить комплексный подход. Видится возможным сформулировать ряд предложений:

- государство должно участвовать в реализации программ по трудоустройству лиц с ограниченными возможностями как работодатель;

- необходимо применение комплексного подхода в рамках трека «образование - прием на работу - доступная рабочая среда»;

- повышение доступа инвалидов к высшему и дополнительному профессиональному образованию является необходимым условием для повышения инклюзивности государственной службы и может быть обеспечено с помощью внесения отдельных пунктов в государственное задание для передовых ВУЗов (например, РАНХиГС при Президенте РФ, МГУ, ВШЭ, МГИМО, Финансовый университет при Правительстве РФ и т.д.);

- метод квотирования может применяться и на государственной службе, как минимум для службы субъектов Российской Федерации;

- смягчение конкурсных процедур не 
должно иметь дискриминационный характер по отношению к лицам без ограниченных возможностей здоровья - снижение объективных требований недопустимо;

- необходимо рассмотреть возможность разработки перечня нарушений здоровья, не препятствующих прохождению государственной гражданской службы (с соотнесением должностей и заболеваний). Информация о доступ- ности должности для лиц с ограниченными возможностями здоровья должна быть размещена в соответствующем разделе Интернет-ресурса «Госслужба» (https://gossluzhba.gov.ru/).

- все вышеизложенные положения могли бы найти отражение в последующих Указах Президента о направлениях развития государственной гражданской службы и соответствующих «дорожных картах» Правительства РФ.

\section{Библиографический список}

1. Об утверждении Порядка прохождения диспансеризации государственными гражданскими служащими Российской Федерации и муниципальными служащими, перечня заболеваний, препятствующих поступлению на государственную гражданскую службу Российской Федерации и муниципальную службу или ее прохождению, а также формы заключения медицинского учреждения: Приказ Минздравсоцразвития РФ от 14.12.2009 N 984н (Зарегистрировано в Минюсте РФ 29.12.2009 N 15878) // СПС Консультант плюс. - URL: http://www.consultant.ru/document/cons_doc_LAW_96619/ (дата обращения: 12.05.2020).

2. Об отмене решения Верховного суда Республики Тыва от 03.03.2011 и признании недействующими пунктов 1, 5-14, 16-21 Приложения к постановлению Правительства Республики Тыва от 01.11.2010 N 464 «Об установлении организациям Республики Тыва минимального количества специальных рабочих мест для трудоустройства инвалидов»: Определение Верховного Суда РФ от 11.05.2011 N 92-Г11-1// СПС Консультант плюс. - URL: http://www.consultant.ru/cons/cgi/online.cgi?rnd=3D4F5A45BF35FFB8C3D2AEE8E604D 6B4\&req $=$ doc $\&$ base $=$ ARB \& $=199796 \&$ REFFIELD $=134 \&$ REFDST $=100006 \&$ REFDOC $=172482 \&$ REFBASE $=$ QUEST \&stat=refcode\%3D10881\%3Bindex\%3D8\#09011330259172079 (дата обращения: 12.05.2020).

3. Занятость инвалидов в трудоспособном возрасте // Пенсионный Фонд Российской Федерации.- URL: https://sfri.ru/analitika/zanyatost/zanyatost?territory=1 (дата обращения: 12.05.2020).

4. Структура занятого населения в возрасте 15-72 года, имеющего инвалидность, по видам экономической деятельности на основной работе // Федеральная служба государственной статистики. - URL: https://gks.ru/ free_doc/new_site/population/invalid/tab4-10.htm (дата обращения: 12.05.2020).

5. The Rehabilitation Act of 1973 // U. S. Equal Employment Opportunity Commission. - URL: https:/www.eeoc.gov/ statutes/rehabilitation-act-1973 (дата обращения: 12.05.2020).

6. The Americans with Disabilities Act of 1990 and Revised ADA Regulations Implementing Title II and Title III // US Department of Justice. Civil Rights Division._- URL: https://www.ada.gov/2010_regs.htm (дата обращения: 12.05.2020).

7. Increasing Federal Employment of Individuals With Disabilities: Executive Order 13548 of July 26, 2010 // Federal Register / Vol. 75, No. 146 / Friday, July 30, 2010 / Presidential Documents. - URL: https:/www.govinfo.gov/ content/pkg/FR-2010-07-30/pdf/2010-18988.pdf (дата обращения: 12.05.2020).

8. Increasing the Opportunity for Individuals With Disabilities To Be Employed in the Federal Government: Executive Order 13163 of July 26, 2000 // Federal Register Vol. 65, No. 146 Friday, July 28, 2000. - URL: https://www.govinfo. gov/content/pkg/FR-2000-07-28/pdf/00-19322.pdf (дата обращения: 12.05.2020).

9. Persons with a disability: Labor Force Characteristics - 2019 // Bureau of Labor Statistics. US Department of Labor. - URL: https://www.bls.gov/news.release/pdf/disabl.pdf (дата обращения: 12.05.2020).

10. Reforming Federal Hiring: A Report to the President and the Congress of the United States // U. S. Merit Systems Protection Board. - URL: https://www.mspb.gov/mspbsearch/viewdocs.aspx?docnumber=224102 \&version=2243 21 \&application=ACROBAT (дата обращения: 12.05.2020).

11. Regulations, Directives, Guidance and Resource Documents // U. S. Equal Employment Opportunity Commission.URL: $\quad$ https://www.eeoc.gov/federal-sector/management-directive/regulations-directives-guidance-andresource-documents (дата обращения: 12.05.2020).

12. Report on the Employment of Individuals with Disabilities in the Federal Executive Branch. Fiscal Year 2015 // Office of Personnel Management.- URL: https:/www.opm.gov/policy-data-oversight/diversity-and-inclusion/ reports/disability-report-fy2015.pdf (дата обращения: 12.05.2020). 